\title{
RESPIRATORY RESPONSE DURING EXERCISE IN PULMONARY FIBROSIS AND EMPHYSEMA
}

\author{
By NOLAN L. KALTREIDER ANd WM. S. McCANN \\ (From the Department of Medicine of the School of Medicine and Dentistry of the University \\ of Rochester and the Medical Clinic of the Strong Memorial and Rochester \\ Municipal Hospitals, Rochester, New York)
}

(Received for publication August 17, 1936)

Numerous tests for cardiac efficiency have been proposed in the past, but relatively little attention has been focused upon breathlessness in patients with respiratory disorders. Fundamental studies of the importance of ventilation in heart disease have been made by Peabody and his fellow workers (1). They demonstrated that the degree of dyspnea was proportional to the reduction in the vital capacity and in the "pulmonary reserve." Harrison and his coworkers (2) recently have studied very thoroughly the pathogenesis of cardiac dyspnea on exertion. They substantiated the work of Peabody in that " a person becomes short of breath when his actual volume of breathing becomes more than a certain fraction of his maximum possible volume and the closer the actual ventilation approaches the maximum possible ventilation the severer dyspnea becomes." In addition, they found that the degree of dyspnea was fairly closely proportional to the expression total ventilation

vital capacity and still more closely related to the ventilation index.

In regard to the pathogenesis of dyspnea in heart disease these investigators believed that it is of nervous origin, due to reflex stimulation of respiration from the muscles, heart and lungs. Christie and Meakins (3) by measuring the pulmonary elasticity and distensibility came to a similar conclusion that breathlessness in patients with heart disease can be explained on the basis of increased sensitivity of the Hering-Breuer reflex due to a decrease in the distensibility of the lungs.

Observations on the respiratory response during exercise on cases other than heart disease have been few in number. Campbell and Poulton (4) investigated this question in cases of chronic bronchitis and found that at rest the minute volume and respiratory rate were increased and during exertion were higher and more prolonged in the group of patients than in the controls.
Attempts have been made to utilize the existing pulmonary reserve by means of the maximum ventilation in order to determine pulmonary function. Sturgis, Peabody, Hall and Fremont-Smith (5) were among the first to obtain the maximum ventilation in response to exercise in normal individuals. Their results showed that the average value for the maximum ventilation was 60.5 liters or approximately 12 times the average breathing volume of such a group at rest. These values were obtained by increasing the respiratory rate to 35 per minute and their tidal volume to 33 per cent of the vital capacity. Hermannsen (6), Jansen, Knipping and Stromberger (7) considered that these values were too low and believed that 100 to 150 liters represented the maximum minute ventilation for male subjects. Marzahn, Gilbeau and Zaeper (8) found in 49 normal individuals that the average maximum ventilation was 70 liters per minute with an average vital capacity of 3.8 liters. In a series of patients with pulmonary emphysema they found the pulmonary reserve greatly reduced.

The respiratory exchange of gases has also been the subject of extensive investigations in heart disease, in an attempt to measure the degree of dyspnea. Herbst (9) studied the amount of oxygen which was absorbed per liter of air inspired, and found that the "utilization coefficient" (amount of oxygen retained by the body out of one liter of inspired air) was reduced in cases of cardiac insufficiency when resting. Knipping, Lewis and Moncrieff (10) and Knipping and Moncrieff (11) applied the "ventilation equivalent for oxygen" (the volume of inspired air that gives up 100 cubic centimeters of oxygen to the body) to cases of cardiac and respiratory diseases. In heart disease, they found that at rest this expression was raised roughly in proportion to the degree of failure present and that on physical exertion there was a further increase, due to the 
fact that the minute volume increased out of proportion to the oxygen consumed. In 2 cases of pneumonia the value for the equivalent was elevated, but in isolated cases of pulmonary tuberculosis they concluded that the test was of no particular value.

Moncrieff (12) recently studied 86 patients with chronic respiratory disease. He divided the patients into five groups on the basis of clinical details, and found that as respiratory efficiency was reduced, there was a reduction in the vital capacity and the "dead space" represented a larger portion of the tidal air. The ventilation equivalent for oxygen, however, showed considerable irregularity.

In order to measure the degree of dyspnea by objective means and to understand better the pathogenesis of shortness of breath in patients with chronic pulmonary disease, the present in- vestigation was undertaken. The ventilation, respiratory rate, tidal volume, oxygen consumption and carbon dioxide production were determined during a standard form of exercise in 20 normal subjects and in 28 patients with cardiorespiratory abnormalities. These results were correlated with anatomical measurements of the lungs and chest and with the gaseous content of the arterial blood. The results are presented in this communication.

\section{METHODS}

In general, the method in these experiments was to collect the expired air at rest, during five minutes of exercise and 3 minutes thereafter. In order that each subject might perform equal amounts of work, an accurately calibrated stationary bicycle ergometer was used (Figure 1). On the main shaft of the ergometer were mounted a heavy fly wheel and an electrical brake. An automobile speedometer was used as a speed indicator,

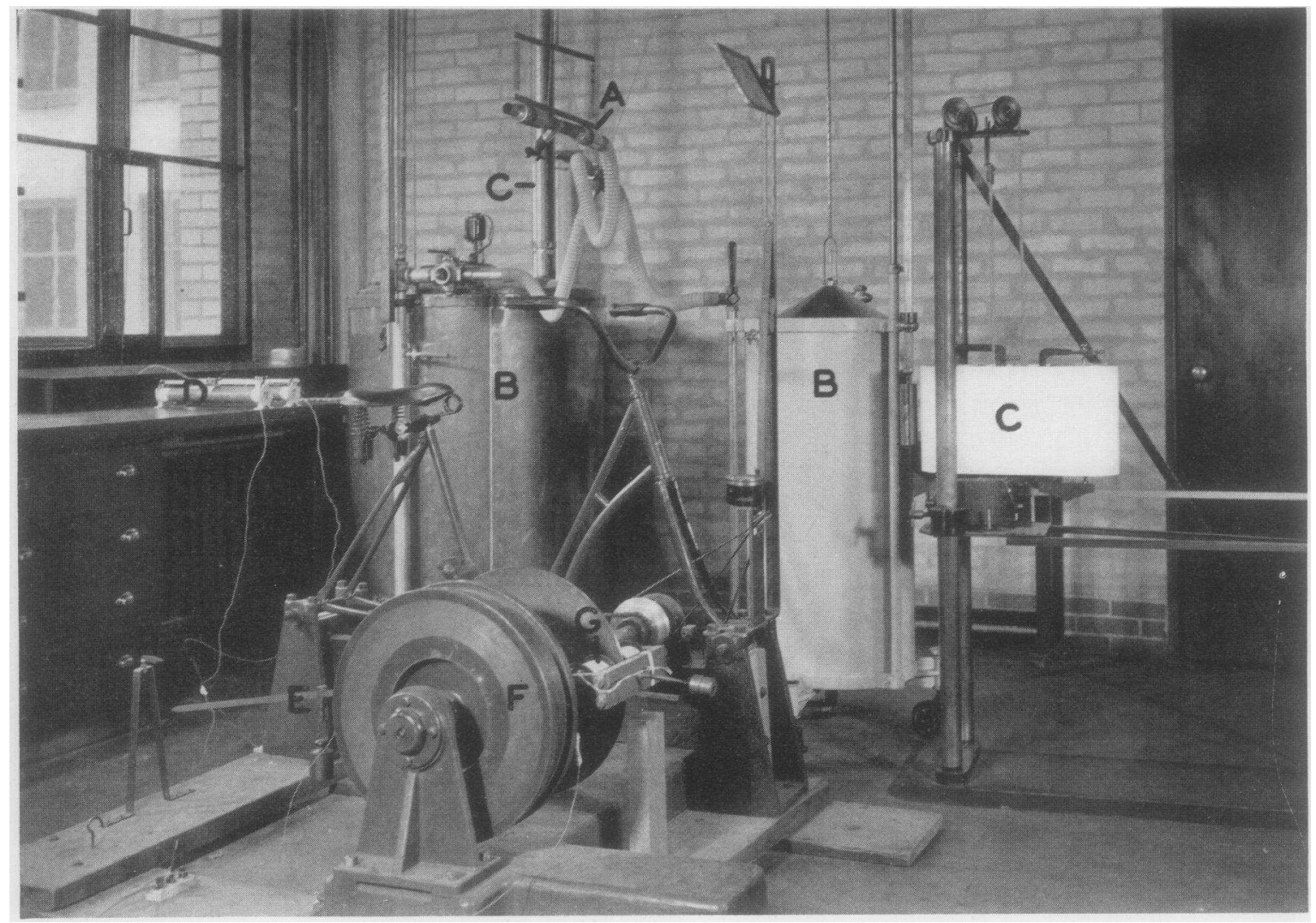

Fig. 1. Bicycle Ergometer.

$A$. Mouthpiece with a set of flutter valves. $B$. Tissot spirometers. $C$. Recording drums. $D$. Rheostats to control the current through the electromagnets of the electrical brake. E. Lever arm of the electrical brake. $F$. Fly wheel. G. Electrical brake. 
the face of which could be readily seen by the subject by means of a mirror. Above the bicycle and suspended from the ceiling of the room was a mouthpiece with a set of flutter valves, so arranged that, during inspiration, air was withdrawn from the room and during expiration it was directed by means of an expiratory valve through a large corrugated rubber tubing to a three-way valve. The connections from the valve were arranged so that the expired air could be collected either in a 150 liter or in a 550 liter Tissot spirometer. Both spirometers were equipped with recording pens and revolving drums.

The course of the experiments was as follows: the subject rested on a chair close to the ergometer for 20 minutes, following which he rested an additional 5 minutes on the seat of the bicycle. The mouthpiece was then connected and the nose clip was adjusted. The three-way valve was turned so that the air was collected for 4 or 5 minutes in the small spirometer. After this period the air was expelled and the procedure repeated. Finally, during the third collection, the period was accurately clocked by a stop watch and the number and volume of each respiration were recorded on the revolving drum. At the end of this period the mouthpiece was disconnected. Samples of the expired air were then withdrawn from the spirometer and analyzed later for carbon dioxide and oxygen according to the method described by Van Slyke and Sendroy (13). Duplicate determinations were made on each sample.

The mouthpiece was then reconnected and during rest the expired air was collected in the large spirometer for one minute. Exactly at the end of that time the subject was given the command "ride." He was instructed beforehand to pedal so that the speedometer registered 30 miles per hour, which corresponded to 67 revolutions of the pedals and 167.5 revolutions of the shaft per minute. At this speed the resistance of the ergometer without a load was 108 kilogrammeters per minute. Weights were so adjusted on the lever arm of the electrical brake that the sum of the resistance of the ergometer and the effect of the brake equalled 300 kilogrammeters per minute. The subject continued to pedal for five minutes, at the end of which time he was given the command "stop." The air was collected in the spirometers during the five minutes of exercise and three minutes of rest thereafter.

After the subject rested for 30 minutes, greater amounts of work were performed for a similar period of time. In the final run, the subject was asked to ride the bicycle as long and as fast as possible, until a state of complete exhaustion was reached.

At the completion of each exercise the subject was questioned concerning respiratory distress, muscle fatigue and other symptoms.

The records were measured and the ventilation and respiratory rate and average tidal volume were determined for each one-half minute. The volumes were reduced to standard temperature and barometric pressure.

The maximum minute ventilation was obtained by averaging the ventilation during the last one and onehalf minutes of maximum exertion, and the pulmonary reserve determined by subtracting the average minute ventilation at rest from the maximum minute ventilation.

The methods of determining the residual air and other components of the total pulmonary capacity as well as the methods of radiographic technique and measurements have been described elsewhere $(14,15)$. The vital capacity was determined both in the lying and sitting positions.

Blood was obtained from the radial artery and stored over mercury in ice water until the analyses were made. Both before and immediately after exercise the blood was secured while the patient was in a semi-recumbent position.

\section{MATERIAL}

This series includes 20 normal subjects, between the ages of 18 and 48 years. The history and physical and fluoroscopic examinations revealed that they were free of any discernible disease. Of the remaining 28 cases, 11 had varying degrees of pulmonary fibrosis, most of which were due to the inhalation of silica; 8 cases of emphysema, all of which except one had histories of repeated attacks of bronchial asthma and 4 of these had co-existing pulmonary fibrosis; 2 cases of chronic bronchitis; 2 cases with histories of attacks of bronchial asthma since childhood, but at the time of examination apparently normal except for clubbing of the fingers in one (H. S.) ; and five cases of rheumatic heart disease ( $\mathrm{Ta}$ ble I).

Complete medical histories were taken and physical examinations were made in each case. None of the patients with pulmonary fibrosis had symptoms or signs of active pulmonary tuberculosis, but many had superimposed bronchial infections and one (S. B.) had repeated attacks of bronchopneumonia during the past 3 years. Two of the patients (S. W., J. B.) had definite evidence of complicating heart disease. Cough and dyspnea on exertion were the two most common symptoms, while clubbing of the fingers was a rarity. The cases of fibrosis were grouped according to the lesion as seen by the radiograph and recently described by McCann, Hurtado, Kaltreider and Fray (16). Varying degrees of emphysema, as evidenced by the increase in the residual air, was shown by the patients with pulmonary emphysema. All the patients with heart disease had mitral stenosis and insufficiency of rheumatic origin and one (S. V.) had in addition aortic stenosis and incompetency. Two of the cases (W. C., J. W.) had mild congestive failure, while 


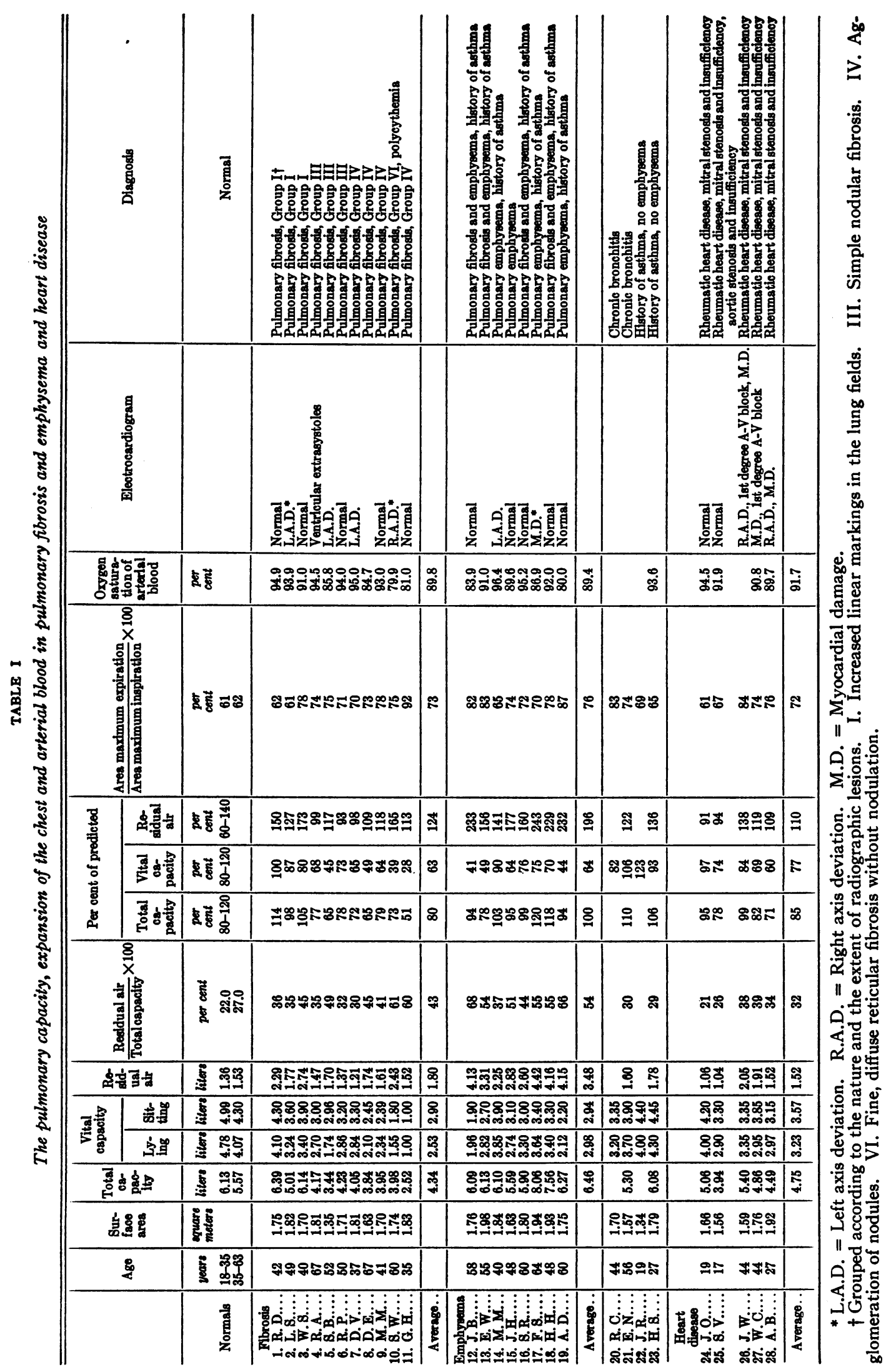


one (A. B.) had moderate failure. The other two cases were well compensated.

The individuals in this series were divided into 4 groups (A, B, C, D), according to disability assessed from their histories. The individuals investigated have been known to us for a period of from one to four years, and we feel that they have been classified as accurately as is possible from clinical details alone.

\section{RESULTS}

Pulmonary capacity and expansion of the chest. Details of the various subdivisions of the pulmonary capacity are presented in Table I. The values given here substantiate those previously reported from this clinic $(17,18)$. Briefly, in cases of pulmonary fibrosis there was a moderate decrease in the total capacity, marked decrease in the vital capacity and a slight rise in the residual air, resulting in a slight increase in the ratio $\frac{\text { residual air }}{\text { total capacity }} \times 100$. As the degree of fibrosis increased, these alterations were accentuated. The patients with pulmonary emphysema showed a normal value for the total capacity, while the vital capacity was greatly reduced and the residual air correspondingly increased. The values for the pulmonary capacity in patients with heart disease were very similar to those with pulmonary fibrosis, i.e., a slight decrease in the total capacity, moderate decrease in the vital capacity while the residual air was slightly increased.

The ability to expand the chest in the three major groups was greatly diminished as evidenced by the increase in the ratio

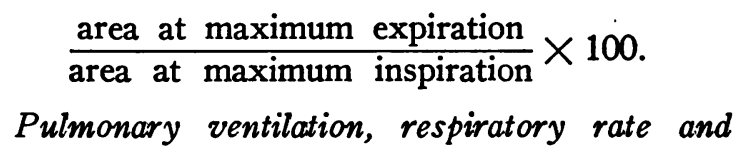
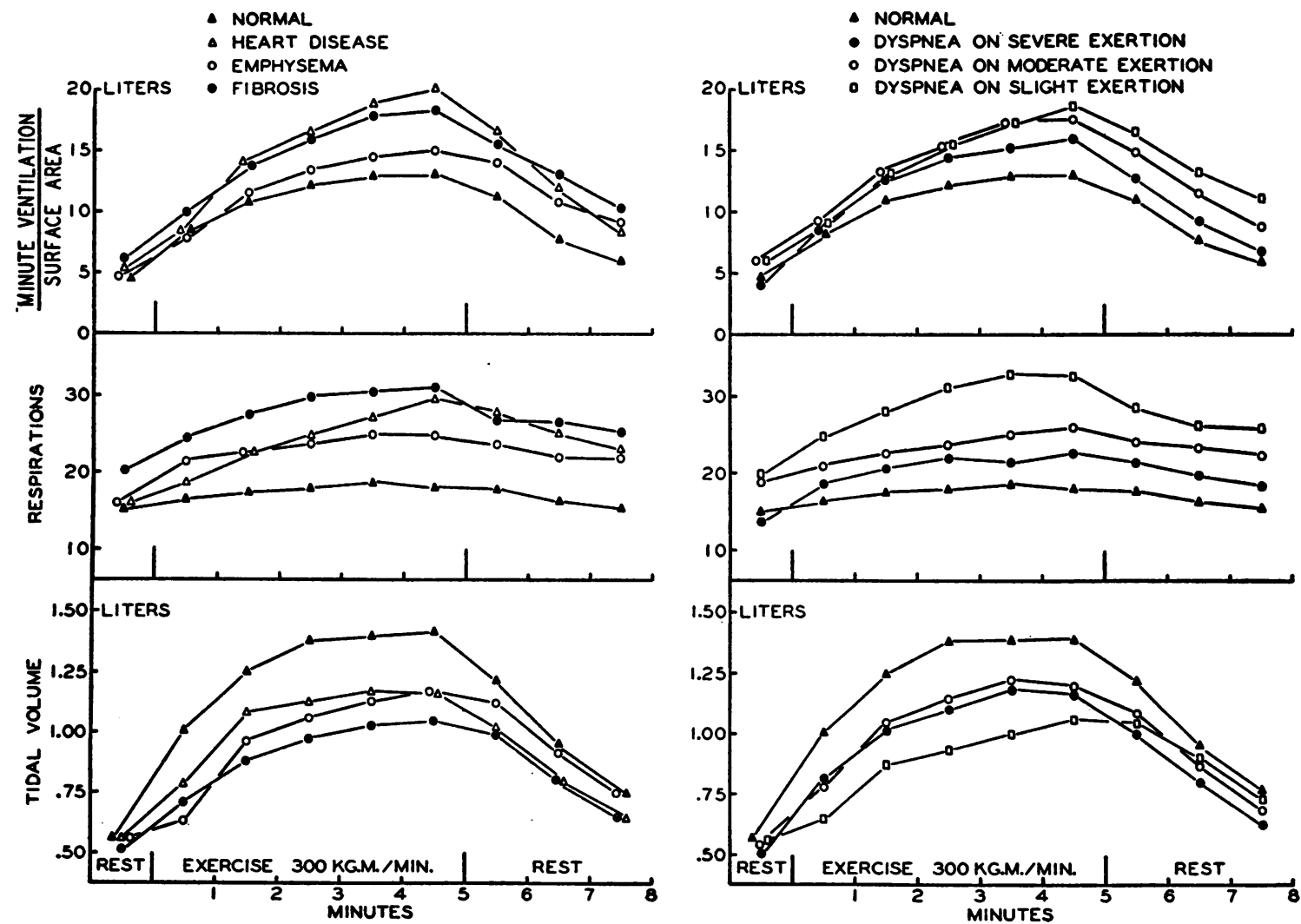

Fig. 2. The Minute Ventilation, Respiratory Rate and Tidal Volume at Rest and During Exercise of Normal Subjects and of Patients with Pulmonary Fibrosis, Obstructive Emphysema and Heart Disease. 
tidal volume. The patients with cardiorespiratory disorders are contrasted with the normal subjects in respect to minute volume per square meter of body surface area, respiratory rate and tidal volume (Figure 2). At rest, the average minute volume of the patients with fibrosis was 6.1 liters or 36 per cent higher than the average value for the normals. The average minute ventilation for the patients with heart disease was 16 per cent higher than the normal controls, while that of individuals with emphysema was 3 per cent higher.

As a result of moderate exercise (300 kilogrammeters per minute for five minutes), the minute volume was increased in all groups, but it reached a considerably higher level in the patients with heart disease and those with fibrosis than it did in the patients with emphysema and the controls (Figure 2). During the fifth and last minute of exercise the average minute volumes for the cases with fibrosis and heart disease were 41 and 54 per cent respectively higher than the controls, while in the patients with emphysema it was only 16 per cent higher.

After three minutes of rest the average values for the minute ventilation were much higher in the three groups than in the normal subjects.

The respiratory rate at rest was considerably higher in the patients with fibrosis than the normals, while the rates of the other two groups were only slightly higher. During exercise, the rate increased in all groups, but the increment was much greater in the patients with heart disease and fibrosis than in the other two groups. At the end of three minutes of rest, the respiratory rate remained elevated in the cases of cardiorespiratory disease, while it returned to the resting level in the control group.

There were equally marked changes in the tidal volume during exertion in the four groups. At rest, the volume of each respiration was essentially the same for the normal subjects and for those with heart disease and emphysema, while the individuals with fibrosis had somewhat smaller tidal volume. During exercise the increase in the tidal volume was greater in the controls than in the patients with cardiac or pulmonary disorders. The smallest increase was in the patients with fibrosis.

An analysis of the second part of Figure 2 shows that in patients who develop dyspnea on moderate or slight exertion, the minute volume and the respiratory rate were greater while the tidal volume was smaller during exercise than in those patients and normal subjects who develop shortness of breath only on severe exertion.

It appears, then, from these results that there is a tendency for higher minute volumes to be associated with higher respiratory rates and smaller tidal volumes. These observations corroborate the studies of Peabody and Sturgis (19) on heart disease. The close similarity of the patients with pulmonary fibrosis and those with heart disease in respect to ventilation during exercise is striking.

\section{The relation of the expression, $\frac{\text { total ventilation }}{\text { vital capacity }}$} to dyspnea. In Table II are presented the results of the total ventilation for 5 minutes of exercise and the following 3 minutes of rest per square meter of body surface area. While performing 1500 kilogrammeters in 5 minutes, the average value for the 20 normal subjects was 83 liters with extremes of 60 and 104 liters per square meter. In 11 cases of fibrosis the total ventilation was greater than that of the controls with an average value of 114 and extremes of 88 and 173 liters per square meter. Similar values were obtained for the 5 patients with heart disease, while 8 patients with emphysema showed values midway between the normal subjects and those with heart disease and fibrosis.

When the patients are arranged according to their disability as estimated from the history, the values for $\frac{\text { total ventilation }}{\text { surface area }}$ increased as dyspnea is more readily produced. The average value for the subjects in Group B, none of whom complained of dyspnea while performing 1500 kilogrammeters in 5 minutes, was 96 , with extreme variations of 74 and 118 liters. In Group $C$ all the individuals except two (R. P. and D. V.) complained of breathlessness while performing this amount of exercise, and the average value for the group was 108 liters. All the patients in Group D noticed dyspnea, and the average value was 114 liters. There was considerable overlapping of the values for the total ventilation in this series as shown in Table III. Thus it appears that $\frac{\text { total ventilation }}{\text { surface area }}$ is only roughly proportional to the degree of dyspnea. These results substan- 


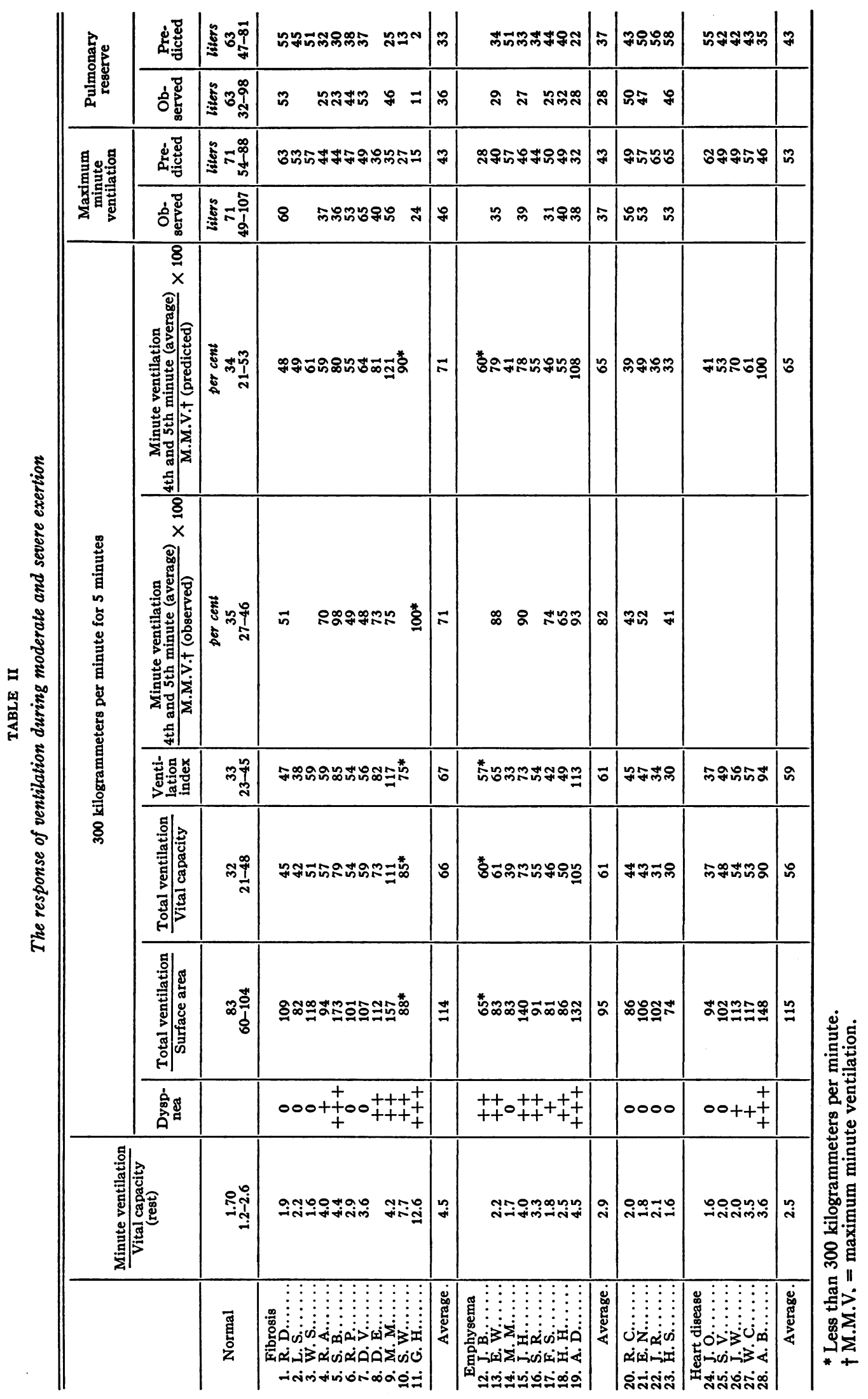




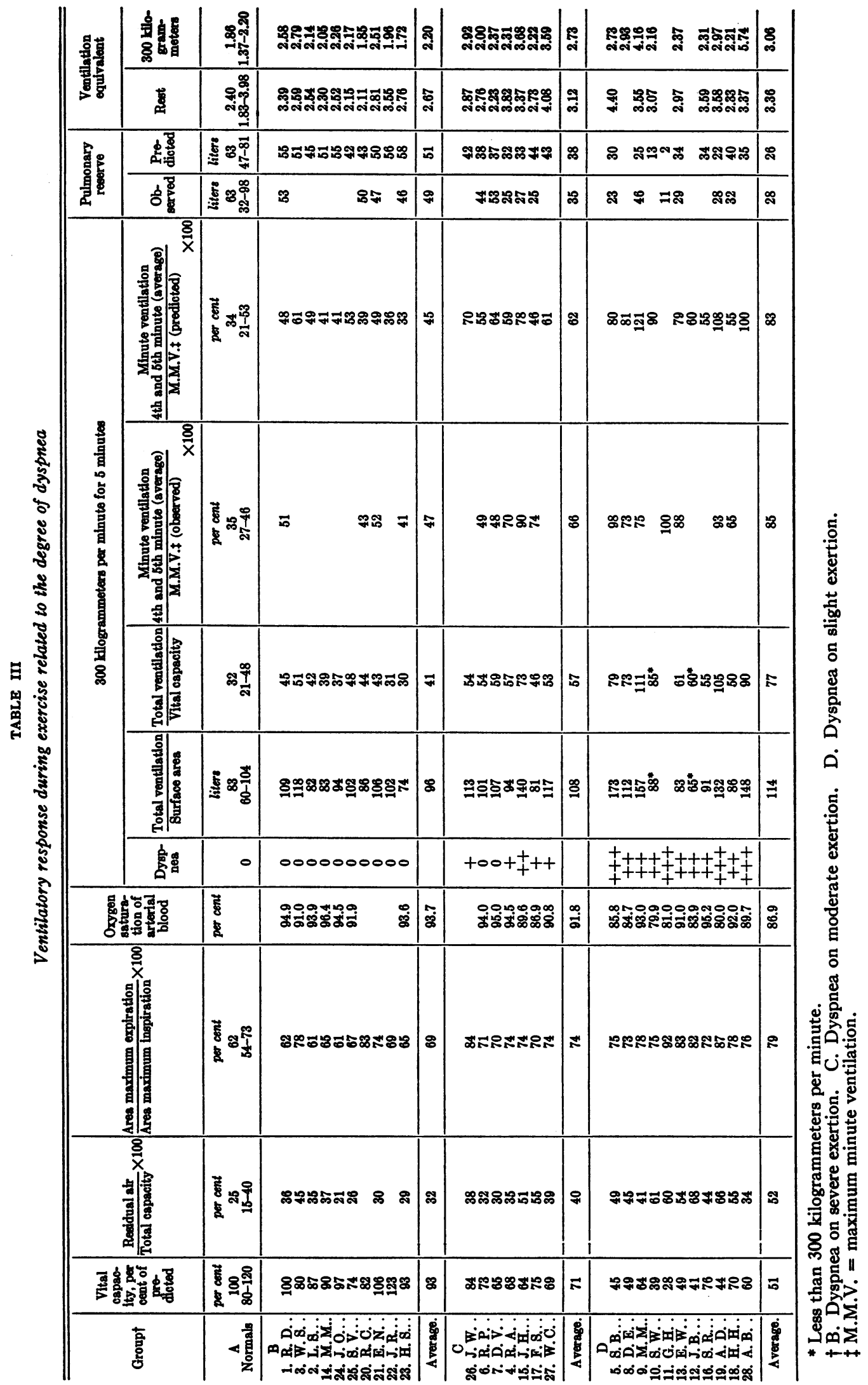


tiate the findings of Harrison and his coworkers (2) in heart disease.

Peabody (1) called attention to the relationship between the vital capacity and the degree of dyspnea in heart disease. It has been shown by Hurtado et al. $(17,18)$ that this relationship holds true in cases of pulmonary emphysema and fibrosis. In this series of cases the relationship between the vital capacity and the ease with which dyspnea is produced is shown in Table III. When the observed vital capacity was less than 70 per cent of the predicted, by the formula of Hurtado and Fray (15), dyspnea was nearly always produced by moderate physical exertion.

Harrison and others (20) found that the degree of dyspnea in heart disease was more closely related to the expression $\frac{\text { total ventilation }}{\text { vital capacity }}$ than to either of these factors alone. The results of this series of cases are very similar to those reported by these investigators. The values for this expression while performing work are given in Table II and Figure 3. At any value below 40 for the expression $\frac{\text { total ventilation }}{\text { vital capacity }}$ none of the individuals complained of dyspnea, while at values between 40 and 66 mild dyspnea was noted. The average value at which breathlessness was noted in all the normal subjects was 51 . As the values for this expression increased the degree of dyspnea became more marked, so that when they approximated 80 moderate to severe distress was experienced. None of the normal subjects noticed shortness of breath while performing 300 kilogrammeters per minute for 5 minutes and all the values were below 48 . As the amount of

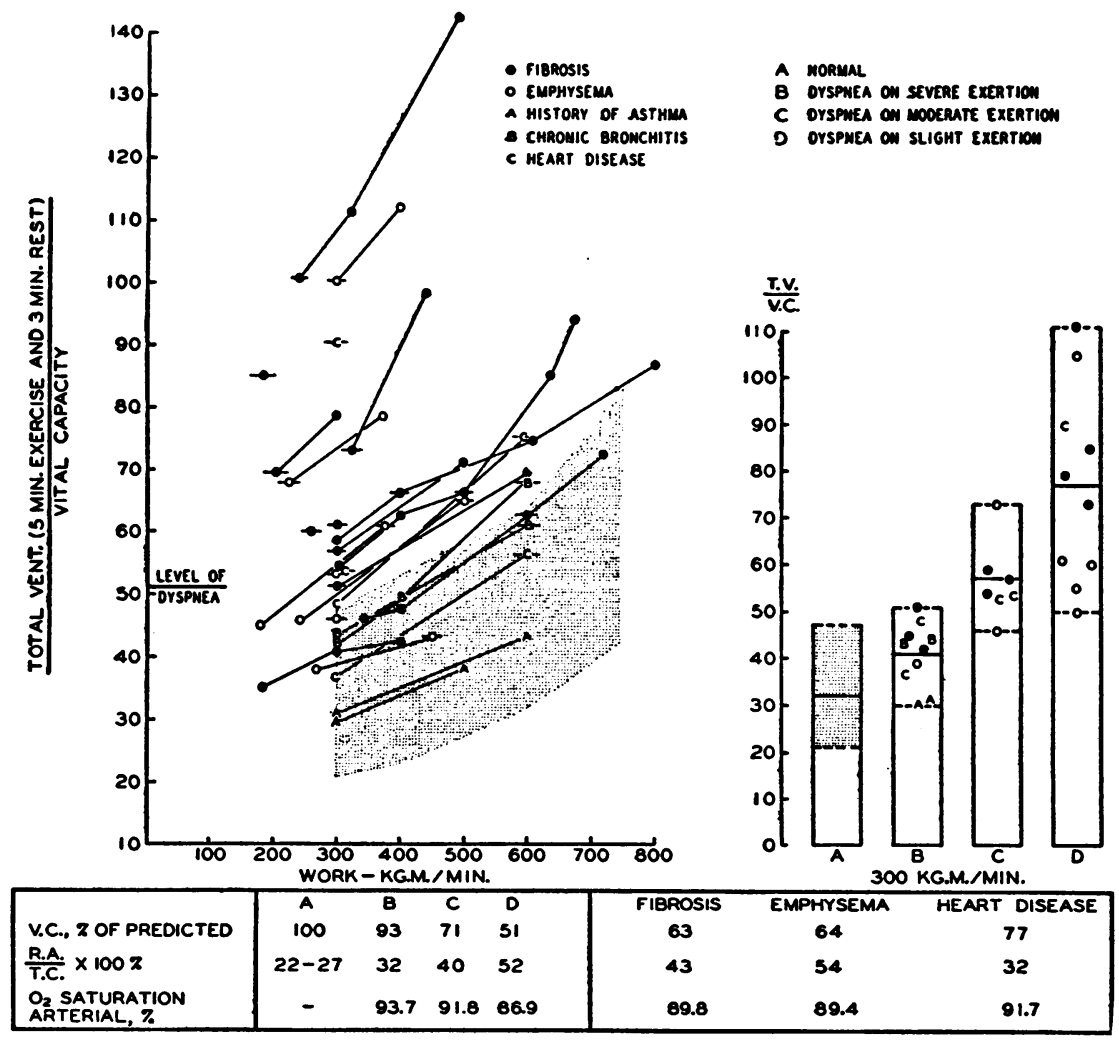

Fig. 3. Relationships between the Expression, $\frac{\text { Total Venttlation }}{\text { Vital Capacity }}$, Work AND THE Level of Dyspnea.

The area shaded with dots represents the range of values for the normal subjects. The horizontal lines through the various symbols designate the value at which dyspnea was noticed. 
work increased from 300 to 750 kilogrammeters per. minute for 5 minutes, the number of normal individuals who developed breathlessness gradually increased as shown in Figure 3. Even at the latter level of work, several of the normal subjects did not complain of dyspnea. This expression appears to be independent of age as the values for the older men were fairly well scattered throughout the normal range.

The individuals with minimal fibrosis (Group I) were well within the limits of normal and did not develop dyspnea until performing 3000 kilogrammeters in 5 minutes. No definite relationship was found between the degree of fibrosis revealed in roentgenographs and the ease with which dyspnea was produced. However, individuals exhibiting typical nodular silicosis showed relatively high values for this expression ( $\left.\frac{\text { total ventilation }}{\text { vital capacity }}\right)$ and in every instance dyspnea was complained of while performing moderate physical exertion.

The two subjects with histories of asthmatic attacks responded as normal individuals, while the two patients with chronic bronchitis were at the upper border or normality. The values for the expression were in accord with the absence of disability.

The values for the expression $\frac{\text { total ventilation }}{\text { vital capacity }}$ are of interest in the cases of pulmonary emphysema. This group complained of dyspnea at relatively low values for this expression. This is in accord with the observations of Hurtado, Fray and McCann (21), who found that patients with emphysema were unable to hyperventilate. The total ventilation per square meter of body surface area in the patients with emphysema was lower than in the patients with pulmonary fibrosis having essentially the same relative vital capacity. The loss of retractile power of the lungs, accompanied by an atmospheric intrapleural pressure, well accounts for their inability to hyperventilate.

During moderate exertion (300 kilogrammeters per minute for 5 minutes) the value for this expression for patients with heart disease ranged from 37 in an individual with well compensated heart disease to 90 in an individual who had moderate congestive failure. The values are in close agreement with the degree of disability as estimated from the clinical findings.

By comparing Groups A, B, C and D in Figure 3 it can be seen that as dyspnea was more readily produced the values for the expression total ventilation

vital capacity increased, the vital capacity decreased, the ratio $\frac{\text { residual air }}{\text { total capacity }} \times 100$ increased and the oxygen saturation of the arterial blood diminished. Although, in general, these statements are true, there was some overlapping of the values among the several groups. This is to be expected in any objective measure of dyspnea, for as Lewis (22) said, "Naturally there is no sharp line of division; there is in a large group of patients a perfect grading from the healthy man to him who is seriously unwell. We are travelling in the borderland between health and disease."

Pulmonary reserve. The maximum minute ventilation obtained in the 20 normal subjects averaged 71 liters with extremes of 49 and 107 liters. The average tidal volume was 41.5 per cent of the vital capacity, and the average respiratory rate was 35.5 at the maximum. These results are similar though somewhat higher than those obtained by Sturgis et al. (5).

There was a marked reduction in the value for the maximum minute ventilation in 8 cases of pulmonary fibrosis. The average value was 46 liters corresponding to an average vital capacity of 2.9 liters. The average value for the highest ventilation in five cases of pulmonary emphysema was somewhat lower, 37 liters per minute, corresponding to a vital capacity of 2.94 liters. With similar values for the vital capacity, the patients with emphysema failed to reach the ventilatory level of those with fibrosis by 9 liters. The patients with fibrosis attained the values for the maximum ventilation by utilizing 44 per cent of the vital capacity and by raising the respiratory rate to 39 , while the individuals with emphysema increased their rate to 30 and the tidal volume to 40 per cent of the vital capacity. The figures given are the average values.

In the series of normal cases, there was no significant correlation between the maximum minute ventilation and the observed vital capacity. 
But when these characteristics of the normal (20 cases) and abnormal subjects (18 cases) of this series and those ( 49 normal subjects and 18 cases of pulmonary emphysema and asthma) reported recently by Marzahn, Gilbeau and Zaeper (8) were correlated, the correlation coefficient became significant, $+0.6169 \pm 0.0605$. If one considers only cases of chronic pulmonary disease in relation to the observed maximum minute ventilation and the vital capacity, the correlation coefficient became more nearly perfect, $+0.7504 \pm$ 0.0491. When the individual values for these two characteristics are plotted against each other the points for the normal individuals are scattered widely on both sides of the regression line, while the values for the abnormal subjects are less widely dispersed. It is possible to predict the maximum minute ventilation from the observed vital capacity on the assumption that the average tidal volume is 41.5 per cent of the vital capacity and average respiratory rate 35.5. A comparison of predicted and observed values is given in Figure 2.

It is noteworthy that the normal individuals in our series stopped riding not because of unbearable dyspnea but because of muscular fatigue, while in almost every instance the individuals with pulmonary disorders were forced to stop because of severe breathlessness. It appears that, in normal individuals not in training, the pulmonary reserve is more than enough to meet any increase in metabolism due to muscular exertion. On the other hand, when the vital capacity is reduced by structural or functional abnormalities as in chronic pulmonary disease, the pulmonary reserve is so reduced that the ventilatory system fails to meet the demands of the heightened metabolism.

The normal subjects had an average pulmonary reserve (maximum minute ventilation minus minute ventilation at rest) of 63 liters, or, in other words, they were capable of a 9-fold increase in their resting ventilation. The patients with pulmonary fibrosis had a reserve of only 36 liters, and those with emphysema, of only 28 liters, and were capable of a more limited increase in resting ventilation (4.6-fold).

It has been pointed out by Peabody (1) that, when an individual uses more than a certain per cent of his maximum ventilation, dyspnea appears. We have investigated this point in our series of subjects. In Figure 4 is plotted the work done against the minute ventilation (average for the fourth and fifth minute of exercise), expressed as percentage of the maximum minute ventilation. Dyspnea was first noticed by normal individuals, when the value for the ratio was between 46 and 70 per cent, with an average value of 59 per cent. The normal average value for the ratio during moderate physical exertion (300 kilogrammeters per minte) was 35 per cent with extremes of 27 and 46 per cent. As the amount of work was increased, the value for the ratio

$$
\frac{\text { minute ventilation }}{\text { maximum minute ventilation }} \times 100
$$

likewise increased, and a larger percentage of the subjects complained of shortness of breath.

When the patients with pulmonary fibrosis performed 1500 kilogrammeters in 5 minutes, the average value for the ratio was 71 per cent. One patient (G. H.), who had extensive fibrosis of the lungs, was actually using 57 per cent of the maximal ventilation at rest and on performing 270 kilogrammeters for $2 \frac{1}{2}$ minutes the actual minute volume of breathing reached the maximum ventilation and dyspnea was extreme. His pulmonary reserve was reduced to 11 liters. On the other hand, the response to exercise by a patient (R. D.) with minimal fibrosis was very similar to the normal individuals. Dyspnea was not produced until he performed 2400 kilogrammeters in 5 minutes when the value for the ratio

$$
\frac{\text { minute ventilation }}{\text { maximum minute ventilation }} \times 100
$$

reached 60 per cent. The pulmonary reserve was great, 53 liters, and only on very severe exertion was he able to exhaust it. The other cases of fibrosis lie between these extremes. The farther the values for this ratio are above and to the left of the normal range in Figure 4 the greater is the degree of dyspnea and the smaller the pulmonary reserve.

Similar findings were observed in cases of pulmonary emphysema. It appears that the pulmonary reserve is a more accurate index of dyspnea in this condition than the expression total ventilation

vital capacity

The maximum minute ventilation was not ob- 


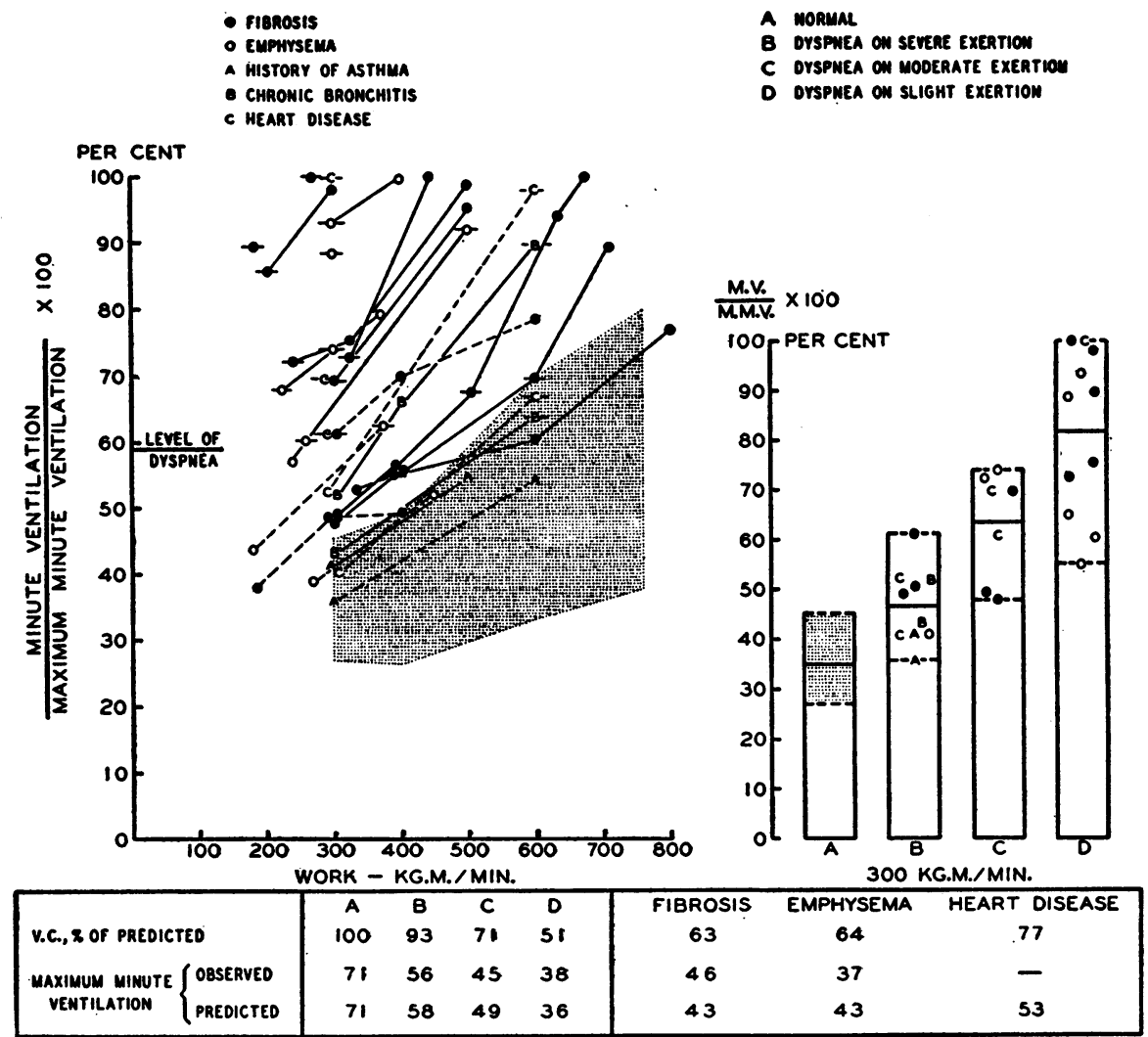

Fig. 4. Relationships between the Ratio $\frac{\text { Minute Ventilation }}{\text { Maximum MinUte Ventilation }} \times 100$, Work ANd the LeVEl of Dyspnea.

The dotted area represents the range of values for the normal subjects. The horizontal lines at the various symbols designate the value at which dyspnea was noticed. The observed values for the maximum minute ventilation were used in the ratio, where the symbols are connected by unbroken lines, while the predicted values were used where the symbols are joined by broken lines.

tained in patients with heart disease. However, if this volume is predicted from the observed vital capacity and the minute ventilation is then expressed as percentage of the maximal ventilation, the values increased during moderate exertion from 41 per cent in the case of J. O., who was compensated, to 100 per cent in the case of A. B. who was in a state of congestive failure. The values for the pulmonary reserve ranged from 62 liters in the former to 46 in the latter.

It is of interest to compare the pulmonary reserve of these individuals when they are grouped according to the disability as estimated from their clinical findings. This comparison is shown in Figure 5. The maximum minute ventilation of Group A (normal subjects) was 71 liters and the minute volume at rest was 8 liters or a reserve of 63 liters. As the clinical condition progressively became worse, the pulmonary reserve decreased, so that the individuals in Group D (dyspnea on slight exertion) had a maximum minute ventilation of only 38 liters and a reserve of 28 liters. When the minute volume at rest was expressed as percentage of the maximum volume, there was a gradual increase in the percentage from 12.4 in the normal subjects to 25.7 in the individuals who developed dyspnea on slight exertion. It is evident that the reduction in pulmonary reserve in those more severely disabled, was due to two factors, reduction in the maximum minute ventilation and an increase in the ventilation at rest. 
During moderate physical exertion the normal subjects utilized only 35 per cent of the maximal ventilation. None of them complained of dyspnea as they still retained 24 per cent of their asymptomatic reserve. Although the individuals in Group B were actually using 12 per cent more of their maximal ventilation than the controls, dyspnea was not noticed as they still had an asymptomatic reserve of 12 per cent. The situation, however, was quite different in Groups C and $\mathrm{D}$. Here the individuals during moderate exertion had not only exhausted their reserve without symptoms but had greatly encroached upon their reserve with symptoms, and shortness of breath was complained of by all but two patients in Group C and by all in Group D.

Similar results were found when the values for the maximum minute ventilation were predicted in each case, Figure 5.
The ventilation equivalent for oxygen. Fortysix subjects were studied in reference to the ventilation per. 100 cc., oxygen absorbed under conditions of rest, and during the fifth minute of moderate physical exertion (Tables III and IV). The average value for the ventilation of normal individuals was 2.40 liters per $100 \mathrm{cc}$. oxygen absorbed, with extremes of 1.83 and 3.98 liters. These values are in close agreement with those reported by Knipping and Moncrieff (11). The average values for this equivalent were increased in all groups of patients with cardiorespiratory disease. The average value in the group with fibrosis was 3.15 with extremes of 2.23 and 4.40 liters, while in that with emphysema it was slightly lower, 2.98 liters. Equally high values were found in the group of five patients with heart disease.

During moderate physical activity the ventila-
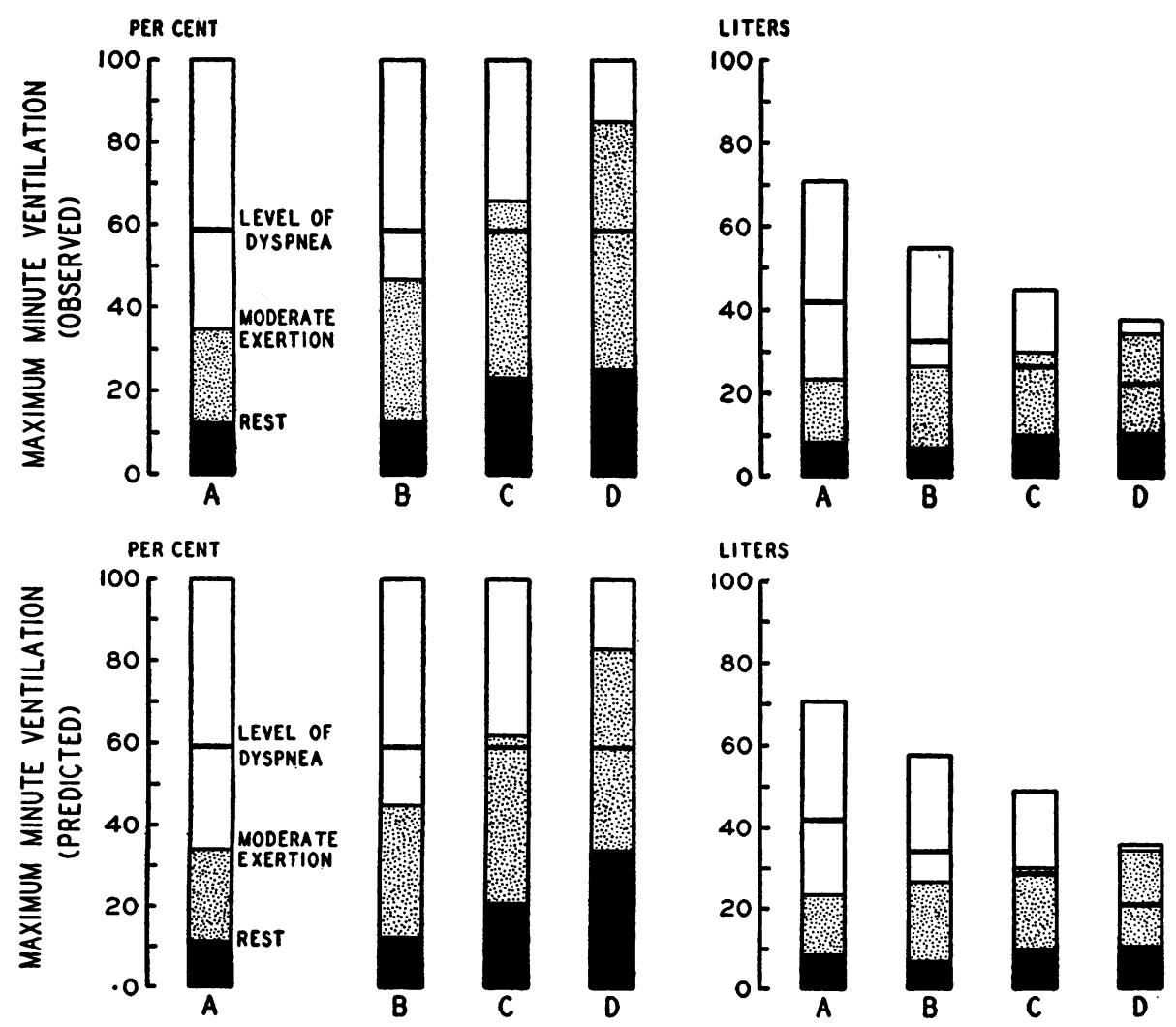

Fig. 5. The Pulmonary Reserve Expressed in Relative and Absolute Values for Normal Subjects and Cases of Chronic Pulmonary Disease and Heart Disease.

Moderate exertion refers to 300 kilogrammeters per minute for five minutes. $A$ designates normal subjects; $B$, patients who develop dyspnea on severe exertion; $C$, dyspnea on moderate exertion; and $D$, dyspnea on slight exertion. 
TABLE IV

Ventilation equivalent for oxygen

\begin{tabular}{|c|c|c|}
\hline & \multicolumn{2}{|c|}{$\begin{array}{l}\text { Ventilation equivalent* } \\
\text { Rest } \\
\text { Exercise }\end{array}$} \\
\hline Normal & $\begin{array}{c}2.40 \\
1.83-3.98\end{array}$ & $\begin{array}{c}1.86 \\
1.37-2.20\end{array}$ \\
\hline $\begin{array}{r}\text { Fibrosis } \\
\text { 1. R. D.. } \\
\text { 2. L. S... } \\
\text { 3. W.S.. } \\
\text { 4. R. A.. } \\
\text { 5. S. B... } \\
\text { 6. R. P.. } \\
\text { 7. D. V.. } \\
\text { 8. D. E.. } \\
\text { 9. M. M. } \\
\text { 10. S. W.. } \\
\text { 11. G. H.. }\end{array}$ & $\begin{array}{l}3.39 \\
2.54 \\
2.59 \\
3.82 \\
4.40 \\
2.76 \\
2.23 \\
\\
3.55 \\
3.07\end{array}$ & $\begin{array}{l}2.58 \\
2.14 \\
2.79 \\
2.31 \\
2.73 \\
2.00 \\
2.37 \\
2.93 \\
4.16 \\
2.16\end{array}$ \\
\hline Ave & 3.15 & 2.62 \\
\hline
\end{tabular}

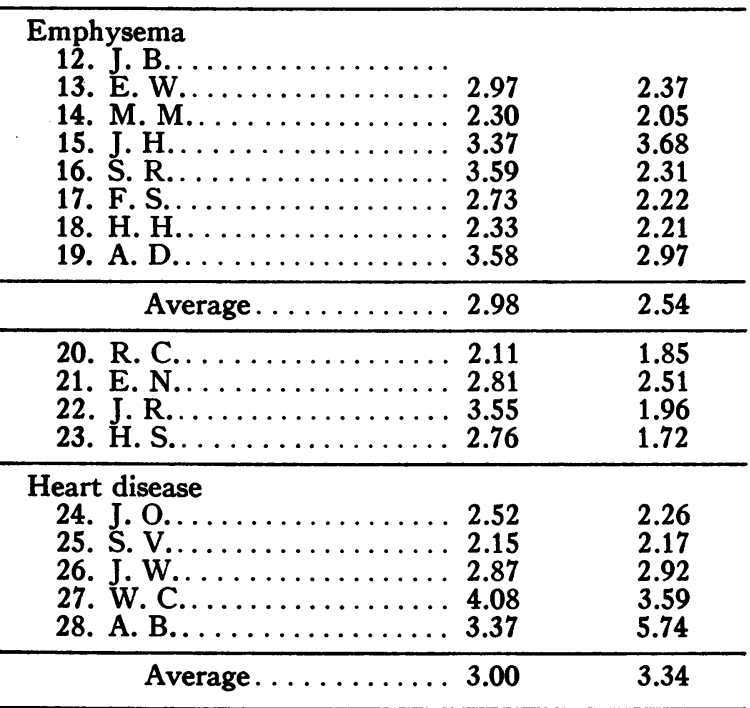

* Ventilation in liters per 100 cc. $\mathrm{O}_{2}$ absorbed.

tion equivalent for oxygen fell in all groups except one, patients with heart disease, in which the values increased from 3.0 to 3.34 liters. Knipping and Moncrieff found that during physical exertion the values for the equivalent remained the same in normal subjects, but increased in patients with heart disease. In the patient A. B., who had decompensated rheumatic heart disease, the value rose from 3.37 at rest to 5.74 liters during exercise, while in the patient J. O., who developed dyspnea only on severe exertion, the value fell from 2.52 at rest to 2.26 liters during exertion.

An analysis of the results in these patients with pulmonary disease when they are arranged in groups according to their disability, showed that at rest the average value for this equivalent increased from 2.4 liters in Group A, to 3.36 liters in Group D. Similar changes were noted during moderate exertion. Although the average values increased as the clinical condition became worse, there were marked individual variations and the overlapping among the several groups was marked. It appears that it is only a fair measure of the degree of dyspnea.

Oxygen in the arterial blood before and after exercise. Blood was obtained from the radial artery at rest and immediately after moderate severe exercise. The results in 9 cases ( 7 cases with pulmonary fibrosis and 2 with emphysema and fibrosis) are presented in Table V. In all

TABLE V

Arterial blood before and immediately after exercise

\begin{tabular}{|c|c|c|c|c|c|c|c|c|c|c|}
\hline & \multicolumn{2}{|c|}{$\begin{array}{l}\text { Carbon } \\
\text { dioxide } \\
\text { content }\end{array}$} & \multicolumn{2}{|c|}{$\begin{array}{l}\text { Oxygen } \\
\text { content }\end{array}$} & \multicolumn{2}{|c|}{$\begin{array}{l}\text { Oxygen } \\
\text { capacity }\end{array}$} & \multicolumn{2}{|c|}{$\begin{array}{c}\text { Oxygen } \\
\text { saturation }\end{array}$} & \multicolumn{2}{|c|}{$\begin{array}{l}\text { Hemoglobin } \\
\text { per } 100 \text { cc. }\end{array}$} \\
\hline & $\begin{array}{l}\text { Bo } \\
\text { fore }\end{array}$ & After & $\begin{array}{l}\text { Be- } \\
\text { fore }\end{array}$ & After & $\begin{array}{l}\text { Be- } \\
\text { fore }\end{array}$ & After & $\begin{array}{l}\text { Be- } \\
\text { fore }\end{array}$ & After & $\begin{array}{l}\text { Be- } \\
\text { fore }\end{array}$ & After \\
\hline & $\begin{array}{c}\text { vol- } \\
\text { umes } \\
\text { per } \\
\text { cent }\end{array}$ & $\begin{array}{c}\text { vol- } \\
\text { umes } \\
\text { per } \\
\text { cent }\end{array}$ & $\begin{array}{c}\text { vol } \\
\text { umes } \\
\text { per } \\
\text { cent }\end{array}$ & $\begin{array}{c}\text { vol } \\
\text { umes } \\
\text { per } \\
\text { cent }\end{array}$ & $\begin{array}{l}\text { nol- } \\
\text { umes } \\
\text { per } \\
\text { cont }\end{array}$ & $\begin{array}{c}\text { vol } \\
\text { umes } \\
\text { per } \\
\text { cent }\end{array}$ & $\begin{array}{c}\text { per } \\
\text { cent }\end{array}$ & $\begin{array}{l}\text { per } \\
\text { cent }\end{array}$ & grams & orams \\
\hline $\begin{array}{l}\text { 5. S. B... } \\
\text { 6. R. P.. } \\
\text { 8. D. E.. } \\
\text { 9. M. M. } \\
\text { 10. S. W.. } \\
\text { 18. H. H.. } \\
\text { 29. L. F. } \\
\text { 30. H. B.. } \\
\text { 31. C. P... }\end{array}$ & $\begin{array}{l}44.3 \\
47.6 \\
49.5 \\
42.6 \\
49.3 \\
48.3 \\
44.7 \\
48.4 \\
41.0\end{array}$ & $\begin{array}{l}39.4 \\
34.8 \\
39.9 \\
32.2 \\
48.3 \\
37.6 \\
40.4 \\
37.5 \\
43.7\end{array}$ & \begin{tabular}{|l|}
16.6 \\
17.5 \\
15.1 \\
17.2 \\
19.8 \\
19.3 \\
17.5 \\
18.4 \\
21.4
\end{tabular} & $\begin{array}{l}17.9 \\
18.7 \\
17.9 \\
19.3 \\
19.3 \\
20.5 \\
18.3 \\
18.9 \\
20.4\end{array}$ & \begin{tabular}{|l|}
17.9 \\
18.6 \\
17.8 \\
18.5 \\
27.7 \\
20.6 \\
20.4 \\
20.0 \\
21.8
\end{tabular} & $\begin{array}{l}18.7 \\
20.3 \\
19.2 \\
20.3 \\
25.2 \\
21.9 \\
20.0 \\
22.1 \\
22.9\end{array}$ & \begin{tabular}{|l|}
92.9 \\
94.0 \\
84.7 \\
93.0 \\
71.8 \\
94.1 \\
85.9 \\
91.9 \\
97.7
\end{tabular} & $\begin{array}{l}95.7 \\
92.1 \\
93.2 \\
95.2 \\
76.7 \\
93.5 \\
91.3 \\
85.3 \\
88.9\end{array}$ & $\begin{array}{l}13.3 \\
13.9 \\
13.3 \\
13.8 \\
20.6 \\
15.3 \\
15.2 \\
14.9 \\
16.3\end{array}$ & $\begin{array}{l}14.0 \\
15.2 \\
14.3 \\
15.1 \\
18.8 \\
18.4 \\
14.9 \\
16.5 \\
17.1\end{array}$ \\
\hline
\end{tabular}

but one case (C. P.), the carbon dioxide content was less after exercise than immediately before. The oxygen content of the arterial blood increased following exercise in all but two cases (S. W. and C. P.) while the oxygen capacity showed a relatively smaller increase in most of the cases so that the oxygen saturation was increased following exercise in all but 3 cases. There was a marked decrease in the oxygen saturation following exercise in 2 cases and a slight fall in two others. All the other individuals responded as normal subjects, i.e., increase in the oxygen content and capacity with a slight rise in the oxygen saturation (Himwich and Barr (23)).

Observations of this nature in patients with chronic respiratory disease are not numerous. Himwich and Loebel (24) found in three patients with pulmonary emphysema that the oxygen con- 
tent increased slightly after moderate exercise in two mild cases while in the third case there was marked reduction in the oxygen saturation as well as in its content. After exhausting exercise the saturation of hemoglobin may fall slightly even in normal subjects (24). Similar decrease was noted by Harrop (25) in a convalescent patient and also in three patients with polycythemia (Harrop and Heath (26)).

Numerous investigators have shown that almost invariably the hemoglobin and the red blood cells increase in both the venous and arterial blood following exercise, both in normal subjects and in patients with various diseases. The red blood cells, hematocrit and viscosity of the arterial blood was determined in 3 cases before and after exercise and in each case they were found to be increased following moderate effort.

\section{DISCUSSION}

From the results presented, it appears that in patients with cardiorespiratory disorders the degree of dyspnea during effort can be expressed fairly accurately in quantitative terms by means of the expression $\frac{\text { total ventilation }}{\text { vital capacity }}$ and the pulmonary reserve. The factors responsible for increased ventilation at rest and for the appearance of dyspnea during moderate exertion in cases of heart disease have been amply discussed by Peabody and his associates (1), Harrison and his coworkers (2) and Christie and Meakins (3). It is our purpose to discuss similar factors responsible for the increase in total ventilation and the reduction in pulmonary reserve, which are usually associated with the appearance of breathlessness on moderate effort in patients with chronic pulmonary disease.

The greater increase in total ventilation in cardiac patients over the normal controls during moderate effort has been shown to be due in part to reflex stimulation of respiration by afferent impulses arising in the heart and lungs $(2,3)$. Although no direct measurements of the rigidity of the lung have been made in fibrosis, it is reasonable to suppose that, due to anatomical changes in this organ, there is decreased distensibility which may well cause increased sensitivity of these reflexes. Harrison and his coworkers (2) believed that an initially high venous pressure and subsequent increase in this pressure during exercise in heart disease over that of the normal controls were important factors in the high total ventilation in such cases. In our series the venous pressure was elevated above the normal limits in 3 of the patients with heart disease, but it was not elevated above the limits of normal in any of the 5 cases of uncomplicated pneumonokoniosis in which it was measured. Thus far there has been no evidence presented in the literature that would indicate the heart is demonstrably involved in pneumonokoniosis which is uncomplicated by infection. Brooks (27), working in our laboratory, found that the cardiac output in patients with fibrosis was unaltered at rest and recently Miller (28) found that the blood velocity in such cases uncomplicated by heart failure was normal in contrast to those with heart disease where it was prolonged. Therefore, one is inclined to believe that the lungs rather than the heart are responsible for the reflex stimulation of respiration in cases of fibrosis. Several of the cases in this group had cardiac involvement and here additional factors are responsible for the increase in total ventilation. Not infrequently an extensive diffuse fibrosis with or without emphysema may give rise to hypertrophy of the right heart and later failure as a result of increased pressure in the lesser circuit due to a great reduction in the capillary bed of the lungs. Two of the patients (S. W. and J. B.) of this series fall into this category.

Factors such as increasing carbon dioxide tension and changes in acid base balance, in addition to those mentioned above, probably play a rôle in the production of dyspnea, but as Wiggers (29) wrote, "Until methods are devised which enable the experimenter to follow successive changes in carbon dioxide and alkali within shorter intervals of time, we may consider it probable that small transient variations are still being overlooked by the experimenter but not by the vigilant respiratory center." Another factor which seems of importance, which has been totally neglected, is the effect of cardiorespiratory disease on the mechanical efficiency of the human body as a machine, that is, on the ratio of energy converted into external work to total energy expenditure.

Aside from the above changes, the point of onset of dyspnea will vary in different individuals 
according to the vital capacity. Peabody and his associates (1) have shown that the appearance of dyspnea is more closely related to the vital capacity than to the total ventilation. In cases of heart disease they found that dyspnea was proportional to the decrease in vital capacity. Hurtado et al. (17) drew similar conclusions in a study of patients with pulmonary fibrosis. The reduction of the vital capacity in the latter affection is probably due to the encroachment of fibrous tissue upon the functioning alveolar air spaces and by fixation of the diaphragm and ribs by pleural adhesions, thereby limiting maximum inspiration and expiration. Reduction in the vital capacity predisposes toward dyspnea, because it lowers the pulmonary reserve by reducing the maximum minute ventilation. The pulmonary reserve in normal individuals is great, and they can increase their resting ventilation by 9 -fold. But in patients with cardiorespiratory disease, not only is the ventilation at rest higher but the minute volume during exertion reaches a higher level than in the normal controls. In addition, due to the reduction in the vital capacity, the highest ventilation that can be maintained is smaller than in the normal subjects. As a result of these alterations the pulmonary reserve in cases of chronic pulmonary disease is reduced and even moderate exertion produces the subjective sensation of dyspnea.

Patients with pulmonary emphysema have a great mechanical disadvantage in ventilating during effort. As a result of the loss of pulmonary elasticity, the intrapleural pressure fluctuates around that of the atmosphere, thereby decreasing the effectiveness of the diaphragm during inspiration. This is accompanied by an increase in the residual air, a reduction in the vital capacity and inefficient alveolar ventilation. The chest is already in the inspiratory position and the responsibility for any further increase in ventilation is placed upon the respiratory muscles. In consequence of the loss of elasticity of the lungs, patients with emphysema, in contrast to normal individuals, are unable to increase both the depth and rate of respiration. Either the depth is increased, accompanied by slower rate, or the rate is augmented at the expense of the depth. This is probably the most important factor in the prevention of hyperventilation on effort in such patients. This has been clearly demonstrated by the results in this series of patients and substantiates the views of Christie (30).

An analysis of the changes in the arterial blood before and after exercise in cases of pulmonary fibrosis and emphysema throws further light on the pathological physiology of such disorders. Since most of the patients with fibrosis responded as do normal individuals in respect to oxygenation of the blood during moderate exertion, it appears that the amount of oxygen diffusing through the alveolar membrane is more than enough to compensate for the increasing rate of blood flow through the lungs. Although there are other factors that influence the saturation of the hemoglobin, Himwich and Barr (23) felt that they may be neglected for these two major ones. Of interest, however, are the cases of pulmonary emphysema and fibrosis which did not respond in the usual manner. These patients responded more like normal individuals performing exhaustive exercises. Under such conditions the saturation of the hemoglobin is decreased, and Himwich and Barr believed that under these circumstances the volume of blood flow may increase to an extent proportionately greater than the increase in oxygen diffusion.

Little is known concerning the rate of blood flow in chronic pulmonary disease during exertion. However, there are certain factors responsible for increasing the alveolar oxygen tension present in normal subjects during exercise that are lacking in patients with marked emphysema. Bohr (31) found that during exercise the residual air was increased in normal subjects. Our preliminary experiments substantiate his observations. Pulmonary distention of this nature will open more alveoli (32), will cause a stretching of the alveolar membrane resulting in a thinner and more permeable one (33), and will increase the ventilation coefficient, since the increase in tidal volume is much greater than the increase in the residual air. This increase in the alveolar air or so-called "mechanical buffer" tends to prevent a rapid fall of alveolar oxygen.

The benefit to be derived from these compensatory mechanisms must be almost negligible in emphysema. Although no measurements of the residual air have been made in emphysema during exertion, it is difficult to conceive how it can be significantly increased when the lungs and chest 
at rest are already in an inspiratory position. Likewise, the relatively small increase in ventilation will not tend to increase the oxygen tension of the alveolar air.

Finally, the factors responsible for the decreased saturation of the hemoglobin after exercise in some cases of pulmonary fibrosis, may well be due to an impediment to the passage of oxygen through the alveolar membrane (Cases S. W. and H. B. had extensive fine reticular fibrosis throughout both lungs), either by thickening of the membrane or by a reduction in the area by the encroachment of fibrosis tissue. Another factor which may play a rôle is rapid and shallow breathing during moderate effort.

\section{SUMMARY AND CONCLUSIONS}

Measurements of the minute volume, the respiratory rate and the tidal volume were made in 20 normal individuals and 28 patients with chronic cardiac and pulmonary diseases during moderate and exhaustive effort. The ventilation equivalent for oxygen was determined at rest and during the fifth minute of moderate exertion. The results were correlated with the pulmonary capacity and its subdivisions, the ability to expand the chest and the oxygen saturation of the arterial blood. Blood was obtained from the radial artery immediately before and after moderately severe exercise in 9 cases of pulmonary fibrosis and emphysema.

From the results presented the following conclusions can be drawn.

1. Individuals with pulmonary fibrosis, rheumatic heart disease and obstructive emphysema have a greater minute ventilation and a more rapid and shallow type of breathing at rest and during moderate exertion than do normal individuals performing the same amount of muscular work. There are striking similarities between the patients with fibrosis and heart disease in their ventilatory response to exercise.

2. The degree of dyspnea is proportional to the expression $\frac{\text { total ventilation }}{\text { vital capacity }}$. Dyspnea is experienced when the value is greater than 51 , and when this value is exceeded at low levels of work ( 300 kilogrammeters per minute for 5 minutes) it is an indication of pathological dyspnea. As the value for this expression increases, the vital ca- pacity and the oxygen saturation of the arterial blood decreases and the ability to expand the chest diminishes.

3. The maximum minute ventilation that can be maintained for one and one-half minutes is only roughly proportional to the vital capacity in normal individuals, while in cases of chronic pulmonary disease the relation is closer. The maximum minute ventilation of an individual may be predicted from the observed vital capacity by assuming that the tidal volume will equal 41.4 per cent of the vital capacity and that the rate of breathing will be 35.5 per minute.

4. The pulmonary reserve is a measure of the tendency to dyspnea. Normal individuals can increase their resting minute volume 9-fold, while in patients who are disabled by pulmonary fibrosis and emphysema, the pulmonary reserve is so reduced that on moderate exertion the ventilation will constitute more than 60 per cent of the maximum minute ventilation.

5. The ventilation per $100 \mathrm{cc}$. oxygen absorbed increases from 2.40 liters for the normal subjects to 3.36 for the patients who complained of dyspnea on slight exertion. It is not a very good index of the degree of dyspnea, since there are marked irregularities in the individual values.

6. After exertion the oxygen content and the oxygen saturation of the arterial blood increases in the majority of the patients with pulmonary fibrosis. In several patients with marked emphysema and fibrosis the oxygen content and saturation were found to be decreased immediately after exercise.

\section{BIBLIOGRAPHY}

1. Peabody, F. W., Cardiac dyspnea. Harvey Lect., 1916-17, ser. 12, 248.

2. Harrison, T. R., Failure of the Circulation. Williams and Wilkins Co., Baltimore, 1935.

3. Christie, R. V., and Meakins, J. C., The intrapleural pressure in congestive heart failure and its clinical significance. J. Clin. Invest., 1934, 13, 323.

4. Campbell, J. M. H., and Poulton, E. P., The effect of exercise on the pulmonary ventilation and rate and depth of breathing in chronic bronchitis. I. Quart. J. Med., 1926-27, 20, 27.

5. Sturgis, C. C., Peabody, F. W., Hall, F. C., and Fremont-Smith, F., Jr., Clinical studies on the respiration. VIII. The relation of dyspnea to the maximum minute volume of pulmonary ventilation. Arch. Int. Med. 1922, 29, 236. 
6. Hermannsen, J., Untersuchungen über die maximale Ventilationsgrösse (Atemgrenzwert). Ztschr. f.d. ges. exper. Med., 1933, 90, 130.

7. Jansen, K., Knipping, H. W., and Stromberger, K., Klinische Untersuchungen über Atmung und Blutgase. Beitr. z. Klin. d. Tuberk., 1932, 80, 304.

8. Marzahn, H., Gilbeau, W., and Zaeper, G., Klinische Untersuchungen über die Function von Atmung und Kreislauf bei Gesunden und Kranken. II. Ergebnisse bei der Prüfung geseunder und kranker Lungen. Ztschr. f. klin. Med., 1936, 129, 434.

9. Herbst, R., Der Gasstoffwechsel als Mass der körperlichen Leistungsfähigkeit. I. Die Bestimmung des Sauerstoffaufnahmevermögens beim Gesunden. Deutsches Arch. f. klin. Med., 1928, 162, 33.

10. Knipping, H. W., Lewis, W., and Moncrieff, A., Uber die Dyspnoe. Beitr. z. Klin. d. Tuberk., 1931, 79, 1.

11. Knipping, H. W., and Moncrieff, A., The ventilation equivalent for oxygen. Quart. J. Med., 1932, N.S. I, 17.

12. Moncrieff, A., Tests for respiratory efficiency. Med. Res. Council, London, 1934, Spec. report ser., 198, 1.

13. Van Slyke, D. D., and Sendroy, J., Jr., Manometric analysis of gas mixtures. I. The determination, by simple absorption, of carbon dioxide, oxygen and nitrogen in mixtures of these gases. J. Biol. Chem., 1932, 95, 509.

14. Hurtado, A., and Boller, C., Studies of total pulmonary capacity and its subdivisions. I. Normal, absolute and relative values. J. Clin. Invest., 1933, 12, 793.

15. Hurtado, A., and Fray, W. W., Studies of total pulmonary capacity and its subdivisions. II. Correlation with physical and radiological measurements. J. Clin. Invest., 1933, 12, 807.

16. McCann, W. S., Hurtado, A., Kaltreider, N. L., and Fray, W. W., Pulmonary capacity and respiratory function in the pulmonary fibroses. Tr. A. Am. Physicians, 1934, 49, 45.

17. Hurtado, A., Kaltreider, N. L., Fray, W. W., Brooks, W. D. W., and McCann, Wm. S., Studies of total pulmonary capacity and its subdivisions. VIII. Observations on cases of pulmonary fibrosis. J. Clin. Invest., 1935, 14, 81.

18. Hurtado, A., Kaltreider, N. L., Fray, W. W., Brooks, W. D. W., and McCann, Wm. S., Studies of total pulmonary capacity and its subdivisions. VI. Ob- servations on cases of obstructive pulmonary emphysema. J. Clin. Invest., 1934, 13, 1027.

19. Peabody, F. W., and Sturgis, C. C., Clinical studies on the respiration. IX. The effect of exercise onthe metabolism, heart rate and pulmonary ventilation of normal subjects and patients with heart disease. Arch. Int. Med., 1922, 29, 277.

20. Harrison, T. R., Turley, F., Jones, E., and Calhoun, J. A., Congestive heart failure. $\mathrm{X}$. The measurement of ventilation as a test of cardiac function. Arch. Int. Med., 1931, 48, 377.

21. Hurtado, A., Fray, W. W., and McCann, Wm. S., Studies of total pulmonary capacity and its subdivisions. IV. Preliminary observations on cases of pulmonary emphysema and of pneumoconiosis. J. Clin. Invest., 1933, 12, 833.

22. Lewis, T., The Soldier's Heart and the Effort Syndrome. Paul B. Hoeber, New York, 1919.

23. Himwich, H. E., and Barr, D. P., Studies in the physiology of muscular exercise. V. Oxygen relationships in the arterial blood. J. Biol. Chem., $1923,57,363$.

24. Himwich, H. E., and Loebel, R. O., The oxygen saturation of hemoglobin in the arterial blood of exercising patients. J. Clin. Invest., 1928, 5, 113.

25. Harrop, G. A., Jr., The oxygen and carbon dioxide content of arterial and of venous blood in normal individuals and in patients with anemia and heart disease. J. Exper. Med., 1919, 30, 241.

26. Harrop, G. A., Jr., and Heath, E. H., Pulmonary gas diffusion in polycythemia vera. J. Clin. Invest., 1927, 4, 53.

27. Brooks, W. D. W. Unpublished data.

28. Miller, H. R., Clinical observations on pulmonary blood flow in silicosis and other fibrotic conditions of the lungs. Am. J. M. Sc., 1936, 191, 334.

29. Wiggers, C. J., Physiology in Health and Disease. Lea and Febiger, Philadelphia, 1934.

30. Christie, R. V., The elastic properties of the emphysematous lung and their clinical significance. $J$. Clin. Invest., 1934, 13, 295.

31. Bohr, C., Die funktionellen Änderungen in der Mittellage und Vitalkapazität der Lungen Normales und pathologisches Emphysem. Deutsches Arch. f. klin. Med., 1906-07, 88, 385.

32. Haldane, J. S., Meakins, J. C., and Priestley, J. G., The effects of shallow breathing. J. Physiol., 1918-19, 52433.

33. Krogh, M., The diffusion of gases through the lungs of man. J. Physiol., 1914-15, 49, 271. 